\title{
Oral carcinoma epidemiology in Paraná State, Southern Brazil
}

\section{Epidemiologia do câncer bucal em pacientes do Estado do Paraná, Sul do Brasil}

${ }^{1}$ Departamento de Genética, Universidade Federal do Paraná, Curitiba, Brasil. 2 Departamento de Biologia Geral, Universidade Estadual de Londrina, Londrina, Brasil.

3 Departamento de Patologia Aplicada, Universidade Estadual de Londrina, Londrina, Brasil.

${ }_{4}^{4}$ Hospital Erasto Gaertner Curitiba, Brasil. 5 Centro Odontológico Norte do Paraná, Universidade Estadual de Londrina, Londrina, Brasil.

Correspondence R. Losi-Guembarovski Departamento de Biologia Geral, Universidade Estadual de Londrina. C. P. 6001, Londrina, $P R$ 86051-990, Brasil. rolosi@uol.com.br

\begin{abstract}
Oral carcinoma is the sixth most frequent type of cancer in the world and the seventh most common in Brazil (the country with the highest incidence in Latin America). Mean five-year survival remains one of the lowest among the main cancers, thus justifying studies that contribute to the development of preventive strategies. The aim of this study was to compare the epidemiological, clinical, and histological characteristics of $91 \mathrm{pa}$ tients with oral carcinoma. Mean age was $58.62 \pm$ 10.46 years, and male-to-female ratio was 6.6:1.0 (79 men and 12 women). European descendants predominated with 79 patients (86.8\%). Eightyfive individuals (93.4\%) smoked and 70 (76.9\%) consumed alcohol regularly. Anatomical distribution of tumors was: 27 (29.7\%) tongue; 18 (19.8\%) floor of mouth; 11 (12.1\%) oropharynx; and 11 (12.1\%) oral mucosa. Fifty-seven patients (62.6\%) presented lymph node involvement and three (3.3\%) had distant metastases. Surgery and radiotherapy were used in $43.2 \%$ of patients. With the exception of the male/female ratio (which was higher), our data are consistent with previous studies on oral carcinoma patients.
\end{abstract}

Mouth Neoplasms; Carcinoma; Oral Health
Roberta Losi-Guembarovski 1,2

Rodrigo Paes de Menezes 2

Fernando Poliseli 2

Vivian Nappi Chaves 2

Hellen Kuasne 2

Andrei Leichsenring 1

Marcos Euzébio Maciel 1

Alda Losi Guembarovski ${ }^{3}$

Benedito W. Oliveira 4

Gyl Ramos 4

Lauro Toyshi Mizuno 5

Iglenir João Cavalli 1

Enilze Maria de Souza Fonseca Ribeiro 1

Ilce Mara de Syllos Cólus 2

\section{Introduction}

Carcinomas of the head and neck constitute a heterogeneous group of diseases with complex molecular abnormalities, and are responsible for high cancer morbidity and mortality. They can originate from pre-malignant lesions due to a process of clonal expansion with the accumulation of genetic alterations. These alterations result in the inactivation of tumor suppressor genes and activation of proto-oncogenes 1 . The affected sites are: oral cavity, pharynx, nasopharynx, hypopharynx, nasal fossa, larynx, and salivary glands.

Among the squamous cell carcinomas of the head and neck, those involving the mouth are the most common. The common term "mouth cancer" refers to a category with different etiologies and histological profiles, although the vast majority of oral tumors are squamous cell carcinomas. Cancers of the oral cavity include those involving the lips, tongue, gingiva, floor of mouth, palate, salivary glands, tonsils, and oropharynx. The etiology is multifactorial, including endogenous factors such as genetic susceptibility as well as environmental and lifestyle exogenous factors like smoking and alcohol consumption 2 .

Oral carcinoma has been identified as the sixth most common type of cancer in the world 3 , with some 390 thousand new cases per year. According to cancer incidence estimates for Brazil in 20064 , there were some 13,470 new cases of 
oral cancer (an estimated 10,060 cases in men and 3,410 in women), thus becoming the seventh most common cancer in the Brazilian population.

Brazil has the highest incidence of oral cancer in Latin America, with major variations between the country's geographic regions. The city of São Paulo has the highest single incidence in Latin America 5,6. According to Boing et al. 7, the mortality rates for oral and pharyngeal cancer are higher in the South and Southeast of Brazil as compared to the other regions of the country, thus highlighting the importance of epidemiological studies in samples from these regions. Clinical presentation is also more severe than in developed countries, with more cases of advanced disease at diagnosis and a higher rate of second primary tumors.

Oral carcinomas are associated with high case-fatality. Although they are amenable to prevention, they have not received sufficient attention by the either the general population or health professionals, so that many cases are diagnosed in advanced stages, with metastases 8 . Tumor size and regional lymph node involvement are the most accurate markers of patient prognosis 9,10. Five-year disease-free survival for oral carcinoma is some $70 \%$ when there is no metastasis at diagnosis and can vary from $30 \%$ to $50 \%$ when metastasis is present 11,12 . Patient survival has remained practically unchanged over the years and is still one of lowest among the main types of cancer. This is believed to result from a combination of late diagnosis and inadequate therapy 9 .

Data from the literature indicate that patient lifestyle influences treatment success, since patients who maintain exposure to risk factors show worse prognosis 11. Intrinsic risk factors include systemic conditions such as malnutrition, iron deficiency anemia, and immune deficiency. The principal extrinsic risk factors are tobacco and alcohol consumption, followed by others such as insufficient fruits and vegetables in the diet and exposure to the human papillomavirus (HPV), especially types 16 and 18 9,11,13.

Generally speaking, the available methods for oral carcinoma detection and treatment have not been efficient in modifying the high incidence and case-fatality rates, thus justifying studies to provide better knowledge of this tumor type's biological profile. The current study analyzed a sample of patients with oral carcinoma in the State of Paraná, southern Brazil, including epidemiological data (age, gender, ethnicity, risk factors) and parameters related to the tumor process (histopathological, clinical, and treatment data) with the objective of better characterizing patients from southern Brazil.

\section{Methodology}

We analyzed 91 patients with oral squamous cell carcinoma, with samples taken at the Erasto Gaertner Hospital (Curitiba), Londrina Cancer Hospital (Londrina), and the Northern Paraná University Dental Care Center (Londrina), selected as referral centers for oral cancer treatment in Paraná State. This sample does not represent all cases of oral carcinoma diagnosed at these sites during the study's collection period, from July 2002 to July 2005. Sample collection was done randomly, based on the possibility of processing the collected specimens.

All patients received information on the research objectives and signed a free informed consent form. Patients were asked to answer a questionnaire with questions on lifestyle, age, gender, ethnicity, and other information. All interviewers received prior training before starting the interviews and sample collection. Information on smoking and alcohol consumption was obtained at the time of the interview, that is, upon diagnosis of the disease. Former smokers who had quit smoking less than ten years previously were classified as smokers. Information on histopathological, clinical, and treatment parameters was obtained from histopathological reports and patients' medical charts. The lack of some information resulted from non-recording on patient charts in the collection centers, even after we consulted the attending physicians (who filled in data in some cases).

Data obtained from interviews and patient charts were used to analyze the following: ethnicity, smoking, alcohol abuse, consumption of hot beverages, family history of cancer (select types based on the literature), tumor location and size, presence of regional lymph node metastases, tumor differentiation, treatment, and death (selected on the basis of availability on the patient charts). The research project was approved by the Institutional Review Boards of the Erasto Gaertner Hospital in Curitiba, the Londrina Cancer Hospital, and the Northern Paraná University Dental Care Center, and by the Brazilian National Committee on Research Ethics (CONEP).

\section{Results}

\section{Sample characteristics}

Table 1 shows the data characterizing the study sample. According to this table, for the $91 \mathrm{pa}$ tients, mean age was $58.62 \pm 10.46$ years and the male/female ratio was 6.6:1.0. Age did not differ significantly between men $(58.29 \pm 10.62)$ and 
women $(60.83 \pm 10.30)(t=0.78 ; p>0.40)$. Ethnic classification was based on facial characteristics and self-classification, with a predominance of European descendants, followed by African descendants and only one Asian descendant. The vast majority of the sample smoked (85 patients, or $93.4 \%$ ). Of these, 40 individuals (47\%) either smoked hand-rolled cigarettes (rolled in cornhusks) or pipes or chewed tobacco, whether or not in addition to smoking manufactured cigarettes. Hand-rolled (cornhusk) cigarettes were the most common, with 37 (92.5\%) of the 40 smokers, while 3 (7.5\%) only smoked pipe tobacco. Formers smokers who had quit less than 10 years previously were classified as smokers. In relation to alcohol abuse, 70 patients (76.9\%) reported frequent alcohol consumption, and of these, $33(47.1 \%)$ consumed distilled liquor, 6 (8.6\%) non-distilled, and 31 (44.3\%) both types (distilled and non-distilled beverages). Scalding hot foods and beverages consumed by 36 patients included chimarrão (matte tea) and coffee. Among patients that reported a family history of cancer, the most common types were tumors of the head and neck and lower digestive tract.

\section{Clinical and histopathological characteristics}

Mean tumor size $(3.40 \pm 1.55 \mathrm{~cm})$ was based on data available for 76 patients.

Of the 91 patients, 27 (29.7\%) had tumors of the tongue and 18 (19.8\%) tumors of the floor of the mouth, the most prevalent anatomical locations in the sample. Eleven patients $(12.1 \%)$ had tumors of the oropharynx, $11(12.1 \%)$ of the oral mucosa (unspecified), 8 (8.8\%) of palate, $6(6.6 \%)$ of the retromolar trigone, and 1 (1.1\%) of the internal lip. Eight patients had tumors in more than one anatomical site, including three of the tongue plus floor of the mouth, one of the mucosa (unspecified) plus trigone, one of the floor plus the palate, one of the tongue plus the trigone, one of the tongue, palate, and trigone, and one of the tongue, floor, and trigone. In one patient it was not possible to ascertain the exact anatomical location of the oral carcinoma.

In relation to the presence of regional lymph node metastases, of the 73 patients with available information, 46 (63\%) showed lymph node involvement and 27 (37\%) had negative lymph nodes. Three patients (3.3\%) presented distant metastases: one in the jejunum, one in the esophagus, and one in the esophagus and lung.

Concerning the degree of tumor differentiation, of the 66 patients with this information, $3(4.5 \%)$ presented well-differentiated tumors (grade I), 39 (59\%) moderately differentiated tu- mors (grade II), and 24 (37\%) poorly differentiate tumors (degree III).

Treatment data were obtained for 74 patients. Thirty-two patients $(43.2 \%)$ received a combination of surgery and radiotherapy, while few patients received other treatment combinations. Six patients $(8.1 \%)$ were submitted to chemotherapy/radiotherapy and $1(1.35 \%)$ received a combination of surgery and chemotherapy. Eighteen patients $(24.3 \%)$ received exclusive radiotherapy, 15 (20.3\%) received exclusive surgery, and $2(2.7 \%)$ received exclusive chemotherapy.

Mortality data were available for 79 patients: 34 (43\%) had died, which may not necessarily reflect the case-fatality rate caused directly by the tumor process.

\section{Discussion}

This study analyzed 91 oral carcinoma patients, with a mean age of $58.62 \pm 10.46$ years, of whom 79 were men and 12 women (Table 1). According to data from the literature, this type of neoplasm is associated mainly with male gender, age around 60 years, smoking, and low income 11,13. Therefore, this sample is consistent with the expected patterns for mean age (58.62 \pm 10.46$)$. In relation to gender distribution, although the literature tends to show a higher proportion in males (with a male/female ratio of 2.0 to 3.0:1.0 according to other authors 14,15), we observed an even higher incidence, with nearly seven times more cases in males as compared to females. Our data show a statistically significant difference in relation to those presented by the Brazilian National Cancer Institute (INCA) 4, which estimated a three-to-one male-to-female ratio for cancer of the head and neck in the Brazilian population $\left(\chi^{2}{ }_{1}=6.8 ; \mathrm{p}<0.01\right)$. We attribute this difference to the fact that our sample was rural and characterized by low income, smoking, and alcohol abuse, common characteristics in the local male population. Huang et al. 16 also explain the heavy predominance of males (74:1) in a sample of patients with oral carcinoma in Taiwan as the result of chewing a carcinogenic mixture of substances by the local populations (especially men).

Epidemiological studies show that tobacco is the main risk factor for developing oral cancer 11,17, due to the fact that it contains some 300 carcinogenic compounds that are converted into reactive metabolites capable of interacting with DNA through the action of oxidative enzymes 18 . Of these, 60 have known carcinogenic action, especially polycyclic aromatic hydrocarbons and tobacco-specific nitrosamines, found in the tar. Other carcinogenic substances like nickel and 
Percentage of patients $(n=91)$

$\begin{array}{lc}\text { Gender } & \\ \text { Male } & 86.8 \\ \text { Female } & 13.2 \\ \text { Ethnicity } & \\ \text { European descendant } & 86.8 \\ \text { African descendant } & 12.1 \\ \text { Asian descendant } & 1.1 \\ \text { Smoker habit } & \\ \text { Yes } & 93.4 \\ \text { No } & 6.6 \\ \text { Alcohol abuse } & \\ \text { Yes } & 76.9 \\ \text { No } & 23.1 \\ \text { Consumption of very hot foods and beverages } & \\ \text { Yes } & 39.9 \\ \text { No } & 60.1 \\ \text { Family history of cancer } & \\ \text { Yes } & 40.6 \\ \text { No } & 59.4\end{array}$

cadmium, radioactive elements like carbon-14 and polonium-210, and even residues of pesticides used in tobacco growing can also be detected in tobacco and tobacco smoke. In addition to the action of carcinogenic substances, continuous exposure to the heat resulting from the tobacco combustion further aggravates the aggression to the oral mucosa. The majority of the current sample (approximately 90\%) consisted of individuals that reported tobacco consumption, often in association with heavy drinking. Among the smokers, we observed a high consumption of hand-rolled cigarettes, pipes, and chewing tobacco, sometimes in addition to smoking manufactured cigarettes. The high proportion of individuals that rolled their own cigarettes in cornhusks is probably a cultural issue, since the vast majority of this sample consisted of individuals from rural areas in the State of Paraná, where this habit is common. According to Damm \& Bouquot 9 , tobacco use without inhaling or "puffing tobacco" in Western culture is considered a strong risk factor in chronic users, highlighting the importance of all forms of tobacco as a potent carcinogen, an inductor of the process leading to this neoplasm.

Some $80 \%$ of patients reported frequent consumption of distilled alcoholic beverages (especially aguardente, or sugar cane spirits, and vod- ka) and non-distilled beverages (especially beer). According to Schlecht et al. 19, the contribution by alcohol to the risk of upper digestive and respiratory tract neoplasms has been described in Brazil not only as an independent factor, but as the effect of interaction with tobacco. Cigarettes and alcohol appear to have a synergistic and dose-dependent effect, generating a twentyfold risk as compared to non-smoking non-alcohol consumers 20,21. Hamada et al. 22 stated that alcohol and tobacco were responsible for oral cancer incidence rates in Brazil comparable to those of India, the country of the world with the highest risk, associated with the habit of chewing tobacco. Although the mechanism by which alcohol induces carcinogenesis is unknown, the hypothesis is that basal and epithelial cells in the oral cavity are altered by high concentrations of ethanol acting directly on the exposed mucosa, and subsequently higher concentrations of carcinogens and pro-carcinogens resulting from its metabolism 18,20. Based on the high number of patients in this sample that reported alcohol consumption, this habit constitutes a risk factor for the development of carcinomas, probably acting jointly with cigarettes.

Some $40 \%$ of patients reported consuming hot foods or beverages, especially chimarrão (matte tea) and coffee. This is probably due to the 
cool climate in the Curitiba region, where most of the study sample was obtained. Data from the literature on the ingestion of hot beverages and foods and oral cancer development are conflicting, with some authors describing this habit as an adjuvant risk factor 23,24 , while others showed a lack of association 25 .

Approximately $40 \%$ of patients reported a family history of cancer, with tumors of the head and neck and lower digestive tract as the most prevalent types. Epidemiological studies suggest family history as a risk factor for cancers of the head and neck, but this fact appears to be more related to a common environment of exposure to cigarettes and alcohol 10, in which individuals from the same family acquire risk habits through family contact. In this study, it was not possible to conduct a more effective analysis of this parameter, since our data only came from patients' self-reported information at the time of the interview, with no actual proof of the presence of other cases in the family, or even anatomopathological proof of the reported tumors.

According to Su et al. 15, prevention is always the best treatment for oral tumors, and knowledge of etiological factors is a prerequisite for any effective preventive measure. In short, patient lifestyle and education are extremely important for preventing this neoplasm. Oral hygiene and regular dental care should be promoted as preventive measures. In high-risk individuals (smokers and alcohol consumers), clinical examination of the mouth should be extremely detailed, and individuals with a suspicion of tumors should be referred to cancer centers for early disease detection, considered the most effective prevention of morbidity and mortality.

According to data from the INCA 4 , in the oral cavity not including the lips, with a high incidence of malignant tumors, the tongue and floor of the mouth are the most frequent sites. Our sample showed the same profile in terms of predominance of anatomical location, since $29.7 \%$ of the patients presented tumors of the tongue and $19.8 \%$ of the floor of the mouth, the two most prevalent (and statistically significant) sites. If we were to assume that probability of occurrence in the various anatomical sites is the same, the difference between expected and observed values was highly significant $\left(\chi^{2}{ }_{7}=39.8\right.$; $\mathrm{p}<0.001$ ), with the main deviation occurring in tumors of the tongue, with a partial $\chi^{2}$ (27.1) representing $56 \%$ of the total $\chi^{2}$. Andreotti et al. 26 , analyzing a sample from São Paulo, also observed that the tongue was the most frequently affected area in both males and females. Meanwhile, Su et al. 15 found an increased prevalence of tumors of the oral mucosa $(29.7 \%)$ in a sam- ple in Changhua, Taiwan. Kuo et al. 27 related the high prevalence of oral mucosa tumors in Taiwan to regional habits involving exposure to a carcinogenic mixture that can include tobacco and would presumably expose the mucosa to high doses of potent carcinogens, which distinguishes this region from elsewhere in the world, where tumors of the tongue are prevalent, as in Brazil. We found only one labial tumor, located on the inner lip, since we chose to exclude external labial tumors from the analysis (samples not collected), given that the predominant etiological factor for external lip carcinoma is exposure to ultraviolet light, unlike most of our sample, in which the main potential risk factors were tobacco and alcohol.

According to Su et al. ${ }^{28}$, the prognostic value of histological grade has shown conflicting results in the literature. Our sample showed only three patients with well-differentiated tumors and a predominance of moderately differentiated tumors, followed by poorly differentiated tumors. Huang et al. 16 found a mortality rate 2.35 times higher in patients with moderately or poorly differentiated (as compared to well-differentiated) tumors and suggested a possible correlation with regional lymph node involvement. However, in our sample two of the three patients with welldifferentiated tumors had cervical lymph node metastases. In addition, the small number of patients with well-differentiated tumors $(n=3)$ prevented us from conducting a more consistent analysis of this issue.

According to data from the literature, tumor size, presence or absence of metastases, and regional lymph node involvement are the most accurate prognostic predictors and influence the determination of type of treatment 9,10. Mean tumor size in this sample was $3.40 \pm 1.55$ $\mathrm{cm}$, and $63 \%$ of patients showed lymph node involvement. According to Perez-Ordoñez et al. 1, approximately $5 \%$ of patients with squamous cell carcinomas of the head and neck develop pulmonary metastases, while most of the esophageal tumors in these patients have an independent, non-clonal origin. Liao et al. 29 report that $14 \%$ of patients with these tumors present distant metastases, with lung and brain as the most frequently involved sites ${ }^{30}$. In the current sample, only three patients had presented distant metastases at the moment in which their medical charts were analyzed, totaling $3.3 \%$ of the sample. Huang et al. 16 and Lin et al. 31 observed distant metastases in $9 \%$ and $15.7 \%$ of their patients, respectively. Our findings show lower values than those described in the literature, but we cannot rule out the appearance of metastases after our analysis was concluded. 
Boing et al. 7 aimed to investigate regional mortality patterns for oral and oropharyngeal cancers in Brazil and observed a decrease in mortality in certain anatomical sites that are easy to access clinically, such as the tongue and palate, correlating this with improvements in the country's health care services in recent decades. It was not possible to follow up patients in the current sample, and the information provided in our study comes only from a two-stage analysis of patient medical charts in 2006. Considering that it was impossible to monitor the patients' clinical evolution, the only information that was identified was the high mortality rate (43\%). However, we do not consider this a reliable parameter for assessing patient prognosis, since it is impossible to state that death was due exclusively to the tumor process.

Treatment is oriented according to clinical and pathological stage and consists of wide surgical excision, radiotherapy, or a combination of the two. Traditionally, chemotherapy is only used in cases of disease recurrence or in the presence of metastasis. More than two thirds of patients with malignant tumors of the head and neck are diagnosed in advanced stages, where surgery followed by radiotherapy has been the standard procedure. In the current sample the largest proportion of patients received a combination of surgery and radiotherapy ( $n=32$ ), that is, following the most commonly adopted or standard procedure, with fewer patients submitted to other forms of combined treatment.
We conclude that the information obtained from analyzing our data is consistent with that expected of malignant tumors of the oral cavity, especially in relation to age at diagnosis, predominance of male gender (despite the even higher male-to-female ratio), and exposure to the principal risk factors. Habits typical to the South of Brazil, including extensive consumption of hot beverages and home-rolled cigarettes were observed and reflect both the cool climate and the prevalence of the rural population's cultural characteristics. Parameters related to the tumor process are quite characteristic and consistent with those described in the literature and in other cancer referral centers. There is an important need to properly complete the patients' medical charts in centers that perform tumor diagnosis and treatment; without such data, it is impossible to obtain reliable information, not only for cancer epidemiolgy, but also for other areas like oncogenetics, currently considered of the utmost importance. In our study, inadequate or incomplete information on patients' charts led to a variable amount of available data for the histopathological, clinical (tumor size, lymph node involvement, differentiation, and death), and treatment parameters evaluated here.

Descriptive and epidemiological studies like this one contribute to the characterization of populations at increased risk for various types of tumors, in addition to fostering a better understanding of patient profiles in the different regions of Brazil.

\section{Resumo}

O carcinoma bucal é o sexto tipo mais comum de câncer no mundo e o sétimo no Brasil, onde ocorre a maior incidência da América Latina. A sobrevida média de aproximadamente cinco anos permanece como uma das menores entre os principais cânceres, justificando estudos que auxiliem no delineamento de estratégias de prevenção. Este estudo objetivou avaliar em uma amostra de 91 pacientes portadores de carcinomas bucais características epidemiológicas; fatores de risco, clínicos e histopatológicos. A média de idade foi de 58,62 \pm 10,46 anos e a razão sexual de 6,6:1,0 (79 homens e 12 mulheres). A etnia euro-descendente foi predominante com 79 (86,8\%) pacientes.
Oitenta e cinco $(93,4 \%)$ indivíduos eram tabagistas e 70 (76,9\%) etilistas. As localizações anatômicas prevalentes foram: 27 tumores (29,7\%) de língua; 18 (19,8\%) de assoalho; 11(12,1\%) de orofaringe e $11(12,1 \%)$ de mucosa. Cinqüenta e sete $(62,6 \%)$ pacientes apresentaram os linfonodos comprometidos e três apresentaram $(3,3 \%)$ metástases à distância. A maioria dos pacientes $(43,2 \%)$ recebeu tratamento cirúrgico e radioterápico. Com exceção da proporção sexual, nossos dados concordam com os freqüentemente descritos para portadores de carcinomas bucais.

Neoplasias Bucais; Carcinoma; Saúde Bucal 


\section{Contributors}

R. Losi-Guembarovski and H. Kuasne participated in the sample collection, data compilation, and writing of the article. R. P. Menezes, F. Poliseli, V. N. Chaves, A. Leichsenring, and M. E. Maciel collaborated in the sample collection and data compilation. I. J. Cavalli contributed to the statistical analysis, orientation, and writing of the article. E. M. S. F. Ribeiro participated in the orientation, project coordination, and writing of the article. I. M. S. Cólus collaborated in the orientation, assistant coordination of the project, and writing of the article. A. L. Guembarovski, B. W. Oliveira, G. Ramos, and L. T. Mizuno participated in the data collection on laboratory reports and patients' clinical data and data compilation and collaborated in the final version of the article.

\section{References}

1. Perez-Ordoñez B, Beauchemin M, Jordan RCK. Molecular biology of squamous cell carcinoma of the head and neck. J Clin Pathol 2006; 59:445-53.

2. Biazevic MGH, Castellanos RA, Antunes JLF, Michel-Crosato E. Tendências de mortalidade por câncer de boca e orofaringe no Município de São Paulo, Brasil, 1980/2002. Cad Saúde Pública 2006; 22:2105-14.

3. Parkin DM, Bray FI, Devesa SS. Cancer burden in the year 2000: the global picture. Eur J Cancer 2001; 37:54-66.

4. Instituto Nacional de Câncer. Estimativa 2006: incidência de câncer no Brasil. Rio de Janeiro: Instituto Nacional de Câncer; 2006.

5. Wünsch-Filho V, Camargo EA. The burden of mouth cancer in Latin America and the Caribbean: epidemiologic issues. Semin Oncol 2001; 28: 158-68.

6. Wünsch-Filho V. The epidemiology of oral and pharynx cancer in Brazil. Oral Oncol 2002; 38: 737-46.
7. Boing AF, Peres MA, Antunes JL. Mortality from oral and pharyngeal cancer in Brazil: trends and regional patterns, 1979-2002. Rev Panam Salud Pública 2006; 20:1-8.

8. Vanderlei FAB, Pereira FC, Hojaij FC, Nishio S. Importância do exame da cavidade oral no diagnóstico precoce de tumores de boca. RBM Rev Bras Med 1998; 77:101-12.

9. Damm N, Bouquot A. Patologia epitelial. In: Neville BW, Damm DD, Allen CN, Bouquot JE, editors. Patologia oral e maxilofacial. Rio de Janeiro: Editora Guanabara Koogan; 1998. p. 287-96.

10. Nagpal JK, Das BR. Oral cancer: reviewing the present understanding of its molecular mechanism and exploring the future directions for its effective management. Oral Oncol 2003; 39:213-21.

11. Scully C, Porter S. ABC of oral health. Oral cancer. BMJ 2000; 321:97-100.

12. Lippman S, Hong WK. Molecular markers of the risk of oral cancer. N Engl J Med 2001; 344:1323-6. 
13. Clark A. Oral cancer prevention and early detection. Nurs Stand 1999; 13:43-7.

14. Chidzonga MM, Mahomva L. Squamous cell carcinoma of the oral cavity, maxillary antrum and lip in a Zimbabwean population: a descriptive epidemiological study. Oral Oncol 2006; 42:184-9.

15. Su CC, Yang HF, Huang SJ, Lian IB. Distinctive features of oral cancer in Changhua County: high incidence, buccal mucosa preponderance, and a close relation to betel quid chewing habit. J Formos Med Assoc 2007; 106:225-33.

16. Huang C, Chu ST, Ger L, Hou Y, Sun C. Clinicopathological evaluation of prognostic factors for squamous cell carcinoma of the buccal mucosa. J Chin Med Assoc 2007; 70:164-70.

17. Zakrzewska JM. Fortnightly review: oral cancer. BMJ 1999; 318:1051-4.

18. Canevari RA, Rogatto SR. Câncer de cabeça e pescoço. In: Casali JC, Ferreira CG, organizadores. Oncologia molecular. São Paulo: Editora Atheneu; 2004. p. 189-201.

19. Schlecht NF, Franco EL, Pintos J, Negassa A, Kowalski LP, Oliveira BV. Interaction between tobacco and alcohol consumption and the risk of cancers of the upper aero-digestive tract in Brazil. Am J Epidemiol 1999; 150:1129-37.

20. Lazarus P, Park JY. Metabolizing enzyme genotype and risk for upper aerodigestive tract cancer. Oral Oncol 2000; 36:421-31.

21. Gaudet MM, Olshan AF, Poole C, Weissler MC, Watson M, Bell DA. Diet, GSTM1 and GSTT1 and head and neck cancer. Carcinogenesis 2004; 25:735-40.

22. Hamada GS, Bos AJ, Kasuga H, Hirayama T. Comparative epidemiology of oral cancer in Brazil and India. Tokai J Exp Clin Med 1991; 16:63-72.

23. Franco EL, Kowalski LP, Oliveira BV, Curado MP, Pereira RN, Silva ME, et al. Risk factors for oral cancer in Brazil: a case control study. Int J Cancer 1989; 43:992-1000.
24. Castellsague X, Monoz N, De Stefani E, Victoria CG, Castelletto R, Rolon PA. Influence of mate drinking, hot beverages and diet on esophageal cancer risk in South America. Int J Cancer 2000; 88:658-64.

25. McLaughlin JK, Gridley G, Block G, Winn DM, Preston-Martin S, Schoenberg JB, et al. Dietary factors in oral and pharyngeal cancer. J Natl Cancer Inst 1988; 80:1237-43.

26. Andreotti M, Rodrigues AN, Cardoso LMN, Figueiredo RAO, Eluf-Neto J, Wünsch-Filho V. Ocupação e câncer da cavidade oral e orofaringe. Cad Saúde Pública 2006; 22:543-52.

27. Kuo MY, Jeng JH, Chiang CP, Hahn LJ. Mutations of Ki-ras oncogene codon 12 in betel quid chewingrelated human oral squamous cell carcinoma in Taiwan. J Oral Pathol Med 1994; 23:70-4.

28. Su HH, Chu ST, Hou YY, Cheng KP, Chen CJ. Spindle cell carcinoma of the oral cavity and oropharynx: factors affecting outcome. J Chin Med Assoc 2006; 69:478-83.

29. Liao CT, Wang HM, Ng SH, Yen TC, Lee LY, Hsueh $\mathrm{C}$, et al. Good tumor control and survivals of squamous cell carcinoma of buccal mucosa treated with radical surgery with or without neck dissection in Taiwan. Oral Oncol 2006; 42:800-9.

30. Lee G, Wong YK, Chang YL, Chang CS. Metastasis in oral squamous cell carcinoma. J Chin Med Assoc 1991; 48:445-50.

31. Lin CS, Jen YM, Cheng MF, Lin YS, Su WF, Hwang JM, et al. Squamous cell carcinoma of the buccal mucosa: an aggressive cancer requiring multimodality treatment. Head Neck 2006; 28:150-7.

Submitted on $03 / \mathrm{Sep} / 2007$

Final version resubmitted on 21/Dec/2007

Approved on 10/Jan/2008 